\title{
Representing Affects and Non-Representational \\ Media Theory
}

\section{GLEN FULLER}

UNIVERSITY OF CANBERRA

\section{Dan Fleming and Damion Sturm}

Media, Masculinities, and the Machine: F1, Transformers, and Fantasizing

Technology at its Limits

Continuum, New York, 2011

ISBN: $9781441115546(\mathrm{hb}) ; 9781623565114(\mathrm{pb})$

RRP US\$120 (hb); US\$30.00 (pb)

Dan Fleming and Damion Sturm's book Media, Masculinities and the Machine explores the question of how the passionate engagements with media and technology by masculine subjects effect a 'reflexive' yet 'constrained' disposition. The authors draw on autoethnographic fieldwork from Sturm's experience of his Formula One (F1) fandom and engage with the complexities of the Transformers franchise (from children's toys to young adult fandom and the intricacies of multigenerational fandom) as their primary examples. Each chapter of the book 
largely involves Fleming and Sturm carrying out a kind of archaeological manoeuvre, digging through the levels of representation to arrive at what they describe as the underlying substrate of affect and examine the ways a particular vitality of affect is materialised in (technological) objects. The key contribution this book makes is to a non-representational media theory that teases out the complex interrelation between mediated elements (texts, objects, and so forth) in the 'affective substrate' of culture. I am focusing on this aspect of the book in this review, rather than the book's other (minor) focus in chapter six on the relation between the technical and the symbolic in the circulation of 'boys toys' and gadgets within popular culture.

The first three chapters mediate the problem of representation and experience through the presentation of Fleming and Sturm's own respective stories. I found reading the third chapter, 'The Scene of Autoaffection' (thus titled with what I suspect is deliberate irony), particularly difficult. This chapter is structured as a dialogue between the authors that begins with a discussion of the previous chapter's autobiographical stories (which are designed to present examples of 'affective labour'). (59) The third chapter is an extended performative example of the tension explicitly captured by Fleming (or at least the 'DF' character) when he writes:

the key question is whether we are thinking of ourselves as preconstituted individuals, with exposure of those selves as the object of autoethnographic attention, or instead we are thinking of a set of daily practices and discourses that constitute the site of the 'self'. (61)

The 'argument' unfolds in the third chapter across and between the dialogue between the two authors, as does (a certain representation of) the affective labour in developing the argument(s). Hence, the irony of 'The Scene of Autoaffection': the 'scene' is not (only) a café in New Zealand as described in the beginning of the chapter, but in the (endlessly deferred, tele-technological) autoaffection of the reader implicated in Fleming and Sturm's argument. (This is what Greg Seigworth means when he describes the book as a 'book-machine' in the book's back-cover material.) I begin with this problematic-autoethnographic 'me' as a masculine subject engaging with an 'interpellating' technological 'gadget' (scholarly text)because Fleming and Sturm explore this question of whether masculine subjects, already fully or partially realised and to what degree, engage with technology, or are 
masculine subjects constituted through specific kinds of social relations with technology. I had to remember how to read with patience (and patience is required when being implicated in someone else's 'autoaffection') so as to properly appreciate their argument.

The contribution to non-representational theory begins in the first chapter as an account of the active practice of surrendering to the particular constellations of affective intensities constituting the 'nesting loops' of popular culture. (35) The nesting loops of Fleming and Sturm's examples in relation to their argument operate like the differentiated serial copper windings of an inductor used to electromagnetically align electrical signals. Here is a sample:

1. The fan-induced pleasure of watching Jacques Villeneuve take a specific corner of F1 track Eau Rouge 'flat out';

2. The musical track 'Jacques, Move Your Body (Make Me Sweat)' by Jacques Lu Cont (a.k.a. Stuart Price) and its sampling of 1980s Detroit electro band Cybertron;

3. The use 'Jacques, Move Your Body' in a 2004 Citroën car commercial involving a transforming and dancing robot;

4. A further series of dancing/moving car/robot commercials and the technological means used to produce them.

This section exemplifies their general method, 'working back through representations in order to track the affective substrate'. (xv) They later isolate the key problematic of the 'non-representational affective layer [they] are looking to trace may significantly disrespect such boundaries' between different cultural texts and sites. (190)

To help the reader grapple with some of the inherent complexity of nonrepresentational relations and process and relations-in-process, Fleming and Sturm dub this cultural articulation as the 'Android Imaginaire'. A central concept in the book, the Android Imaginaire is defined, in part, as a response to Donna Haraway's notion of the cyborg. Instead of working against gendered and scientific essentialisms (as per the 'ironic' cyborg), so that the 'cyborg is a condensed image of both imagination and material reality,' ${ }^{1}$ the Android Imaginaire is Fleming and Sturm's answer to Haraway's question, 'What about men's access to daily competence, to knowing how to build things, to take them apart, to play?' Rather than the leaking of 
boundaries represented by the cyborg, the android is a more direct surrendering of the human to the machine. (28)

They concern themselves with the relation between 'grace' and 'tools' at the different levels of analysis to think about this Android Imaginaire. For example, Villeneuve's grace taking the corner while using the tool of the F1 race car or the grace of dancer's body in the motion capture device for the Citroën advertisement transduced to the screen through the movements of the CGI robot. (34) ('Grace' is mentioned a number of times throughout the book after being introduced on page 34 , but not defined in any succinct manner until page 189; I could see how this definition would be relevant to the discussion one hundred and fifty pages earlier.) This notion of 'grace' is important because Fleming and Sturm suggest that Gumbrecht's correlative notion of 'fascination' captures a sense of how fans of technology relate to the 'grace' of such technology (toys, motorsport, CGI) in different ways. Gumbrecht argues that through 'this ability to fascinate, sports exerts a transfiguring power, drawing his [or her] gaze to things he [or she] would not normally appreciate.'2

Fleming and Sturm connect Gumbrecht's position regarding the ability of 'grace' to 'fascinate' with Baudrillard's critical appraisal of consumer practices as manifesting banal or fatal strategies for a consumer's wilful (if ironic) surrender to a given socio-technological site of fan individuation. Writing about Formula One and metal music, they argue that:

Both offer a wall of sound and a flurry of speed that does not need to be representationally elaborated, although of course it is: their intensity first grips people in an uncomplicated, direct, and vivid manner. Affect materialises as an intense soundscape and spectacle of speed. (57) It is difficult to agree with this. There are particular (sub)cultural practices that nonfans, non-enthusiasts or non-participants find abrasive, distasteful, boring and generally a negative experience. The capacity to be open to the experience of Formula One or metal-their intensities-is surely a question of comportment (habitus and so on), but also in the way that participants need to become gradually immersed. I am not suggesting a necessary critical disposition by fans, but more an appreciation of taste as a performative practice involving the mastery of techniques and socio-technologies of fandom. ${ }^{3}$ 
Fleming and Sturm invert the transmission of the respective events into the lounge room, so the 'fascination' of the viewer (what they are documenting in their ethnographic work) projects back onto the technology:

Where Villeneuve did not have time to think, thanks to the charmed technology of speed and aerodynamics, the robot-car has no means to think. And yet the grace of human presence is still there, thanks in this case to the charmed technology of motion capture. (24)

What does 'does not have time to think' or 'no means to think' mean? The projection of human intellectual capabilities onto a complex socio-technical assemblage involving complex distributions of agency is simplistic. Formula One is complicated by there being a 'live' event somewhere, but the Citroën advertisements (mentioned above) are massively more complicated if the notion of 'liveness' is imagined as distributed across multiple production sites and networks of sociotechnical agency in its production. Like Villeneuve taking the corner, the dancing robot's grace is a special effect of the complex socio-technical network that is required to produce it. The tension here is between what is actually being repeated for the Formula One or Transformers fans-the 'grace' exhibited by the object of their 'fascination' or the process of individuation through the (impersonal) experience of being 'fascinated' catalysed by a combination of specific material (asignifying) signs?

Intensity is defined in Fleming and Sturm's glossary as the 'degree of potential that the body has for affective engagement with objects'. (212) For them it is a question of the intensity of affect as a degree of 'fascination' with the 'grace' of a technological ensemble. Another theoretical line (via Bergson, Deleuze, Simondon, Massumi) maps how the intensive dimension of mediated experiences in part work to account for the way the viewer-body is individuated. There is an important difference here. The concept of an 'affective substrate' is primarily understood by Fleming and Sturm (88-9) following Grossberg's work where it functions as an quantitative intensity that is invested by 'fans', albeit inverted here so it is a kind of sublime grace of the object that manifests intensity; as they write in an example about sound 'affect materialises as an intense soundscape'. (57) Such an approach 
pushes to the background those event-based dimensions of experience; this includes, but is not limited to:

1. Affect that circulates across homosocial bodies in-relation and serves as a kind of social glue, such as in Eve Sedgwick's work on 'homosociality';4

2. Relations of excitement or disappoint relating to future or past events, such as Paul Hodkinson's work on Goth subcultures and the role of events in their fandom; 5

3. The differential repetition of childhood experience as an adult to manifest childlike emotional responses, which could be thought of in this context as affective 'nesting loops' of the habitus. See, for example, Felix Guattari's interpretation of Daniel Stern's work. ${ }^{6}$

An example of the simple representation of the qualitative shifts in affective relations within which technological objects find themselves is the Gartner Hype Cycle.7 It tracks the different affective states that a single 'technology' (Gartner has a sophisticated definition of technology, it is not a simple object), from the peaks of 'hype' to diminished 'disappointment' to stable 'trust'. Gartner works to help capitalists make investment decisions so as to minimise risk. These phases in the 'hype cycle' indicate different compositions of relations and qualitatively different affective relations. The key difference here is that the immanent and mobile compositions of affective relationships individuate individuals and collectively individuate entire cohorts (audiences, target markets and so on) instead of individuals using 'affective relationships to anchor, move and re-anchor themselves in an ongoing way within specific temporal and spatial circumstances'. (89)

'Reflexive deliberation' that qualifies 'their intensities' (89) is not enough, because the individual has already been individuated as such-the post-Kantian point being made here is that the capacity for reflexivity (critical judgement) is already after (and before and at the same 'time') the sensations of one's one affective comportment and the affects circulating through the media. Excitement over the latest gadget or Transformers film is not solely a product of the gadget or film; there is a massive media apparatus of techniques and technologies designed to induce 'excitement' as the 'excited individual'; it is the 'excited individual' that pre-books or pre-orders the 'next' thing. From Silvan Tomkins we know that excitement is but one co-assembly of affect and desire; ${ }^{8}$ its manifestation in (masculine) bodies is through 
the mobilisation of these bodies, these bodies might be more responsive to such technics of excitement, but it is a collective process through which the activation contours of excitement individuates 'fans' and 'blockbusters'.

Furthermore, by analysing the representational layer to anchor the affective, are Fleming and Sturm not 'fatal' (in Baudrillard's sense) enough in their strategy? Without a doubt such a slippage actually occurs for some in the audience, but the conditions by which this projection back from representation to 'fascination' occurs cannot be assumed. I agree with Fleming and Sturm that there is a complex passage (or 'non-local linkage') 9 between events of experience, which they indicate may not be apparent through any normative representational structure or straightforward in terms of 'identity', but tracing this through the representational layer assumes too much of the work of the representational text itself. Fleming and Sturm are clearly aware of this point when they suggest that the 'nonrepresentational affective layer we are looking to trace may significantly disrespect such boundaries' between popular genres forms such as Transformers and Formula One. (190) Why stop at boundaries between genres of popular culture? It seems that if there can be such a connection between the fan's investment in Formula One and the Transformers franchise, then why not such a connection between the layers of subjectivity, between the intensities of memory and amodal embodiment of any number of past (and possibly future, unfolding) events that constitute the transversal movement of affect through experience?

These theoretical quibbles, although not minor, should not preclude researchers interested in affect and the media from engaging with Fleming and Sturm's text. Curiously, Fleming and Sturm are aware of the banality of their research objects when they ask the question of what happens when 'interests in motor racing fandom and boys' toys' seem to tell a story 'not just of the deradicalized banality of the humanities in the technocratic university, but of how the field of cultural studies has eventually disappeared up its own trivia?' Their answer is disarmingly honest: 'This small book is what happens'. (2) 
Glen Fuller completed his $\mathrm{PhD}$ in 2007. In it he investigated and problematised the relation between enthusiasm and niche or specialist media. From 2008 to 2011 he worked in the magazine industry in a number of different positions and since 2002 has also worked as a freelance writer. He is currently an assistant professor in Journalism and Communication, Faculty of Arts and Design, University of Canberra.

-NOTES

${ }^{1}$ Donna Haraway, 'A Cyborg Manifesto: Science, Technology, and Socialist-Feminism in the Late Twentieth Century', Simians, Cyborgs and Women: The Reinvention of Nature, Routledge, New York, 1991, pp. 149-81.

2 Hans Ulrich Gumbrecht, In Praise of Athletic Beauty, Belknap Press, Cambridge, 2006, p. 16. A problem for Fleming and Sturm's readers (including me) is that Gumbrecht does not draw on any of the familiar theoretical influences prevalent in cultural studies or its cognate areas. An introductory or biographical note to Gumbrecht's work would have been useful, but it is not essential if readers have access to further scholarly resources.

${ }^{3}$ Antoine Hennion, 'Music Lovers: Taste as Performance', Theory, Culture \& Society, vol. 18, no. 5, 2001, pp. 1-22.

4 Eve Kosofsky Sedgwick, Between Men: English Literature and Male Homosocial Desire, Columbia University Press, New York, 1985, p. 2.

5 Paul Hodkinson, Goth: Identity, Style, and Subculture, Berg, New York, 2002, p. 107.

6 Felix Guattari, Chaosophy, Semiotext(e), New York, 1996, p. 6.

7 Gartner, 'Hype Cycles', <http://www.gartner.com/technology/research/methodologies/hypecycle.jsp>.

8 Eve Kosofsky Sedgwick and Adam Frank, 'Shame in the Cybernetic Fold', Shame and Its Sisters: A Silvan Tomkins Reader, ed. Eve Kosofsky Sedgwick and Adam Frank, Duke University Press, London, 1995, pp. 8-9.

9 Brian Massumi, Semblance and Event: Activist Philosophy and the Occurrent Arts, MIT Press, Cambridge, MA, 2011, pp. 106-9. 